\title{
AВТОРЕФЕРАТЫ
}

\section{КАТЕГОРИЯ ТЯЖКИХ ПРЕСТУПЛЕНИЙ ПО СОВЕТСКОМУ УГОЛОВНОМУ ПРАВУ}

\author{
Кадников Н.Г.
}

\begin{abstract}
Аннотация: Анализ развития уголовного законодательства после 1917 г. показывает, что в силу ряда объективных и субъективных факторов не произошло должной преемственности 8 отнотении норм о классификации преступлений. Возобладал классовый подход в формировании различных групп и видов преступных деяний, а впоследствии классификаиия преступлений вообще утратила свое практическое значение. Несовершенство классификации преступлений в действующем законодательстве отметили $96 \%$ практических и $92 \%$ научных работников, опрошенных в ходе экспертного опроса специалистов. 91 \% проинтервьюированных научных и $88 \%$ практических сотрудников высказались за введение в Общую часть уголовного закона специальной нормы о классификации преступлений с учетом степени их общественной опасности. Методологическую основу исследования составляют теоретические положения материалистической диалектики, литература по философии, логике. В качестве юридичской основы использовались нормы действующего уголовного, уголовно-процессуального, исправительно-трудового и других отраслей права. Важная роль отведена анализу уголовного законодательства дореволюиионной России и других государств. Многие аспекты работы рассматривались в развитие Основ уголовного законодательства Союза ССР и республик, принятых 2 июля 1991 г. Диссертантом предлагается редакиия статьи о категории тяжких преступлений:Статья... Категория тяжких преступлений.1. К тяжким преступлениям относятся умышленные действия, посягающие на жизнь и здоровье человека, собственность, порядок управления, деятельность государственных учреждений и органов правосудия, совершенные опасным способом или причинившие тяжкие последствия, за которые законом предусмотрено наказание в виде лишения свободы на срок от 5 до 10 лет.2. Закон определяет следующие группы тяжких преступлений:- тяжкие преступлена А, за совершение которых законом предусмотрено наказание в виде лишения свободы на срок от 8 до 10 лет;- тяжкие преступления Б, за совершение которых законом предусмотрено наказание в виде лишения свободы на срок от 6 до 8 лет;- тяжкие преступления $B$, за совершение которых законом предусмотрено наказание в виде лишения свободы на срок от 5 до 6 лет.В заключении сформулированы основные выводы диссертации, наиболее значимые из которых изложены в настоящей рукописи при характеристике соответствующих разделов работы.
\end{abstract}

Ключевые слова: Реформа, роль, отрасль, уголовное право, криминология, Признаки, преступления, классификация, борьба, санкиия. 
Актуальность темы исследования. Реформы, происходящие в нашем государстве и обществе, диктуют необходимость кардинальных изменений в законодательной деятельности. Важная роль отводится такой отрасли, как уголовное право, которое затрагивает судьбы практически всего общества, всех его граждан. При реформе уголовного права необходимо учитывать, чтобы его нормы отвечали принципам гуманизма, справедливости, чтобы они впитали в себя весь опыт мировой уголовно-правовой мысли, в том числе и опыт дореволюционной России, и вместе с тем не отбрасывать то положительное, что выработано в теории советского уголовного права. При совершенствовании уголовного законодательства важное значение отводится вопросам разграничения преступных деяний по степени их общественной опасности, то есть их классификация на различные группы. Классификация преступлений в действующем уголовном законодательстве, по нашему мнению, отличается незавершенностью. Выделенная в законе категория тяжких преступлений имеет перечень деяний далеко не равнозначных по тяжести, что находит отражение в размерах санкций. При этом уравниваются особо тяжкие, и тяжкие преступления. Отсутствуют нормы, закрепляющие уголовно-правовые последствия для лиц, совершивших тяжкие преступления. Более того, поскольку и действующая система учета преступлений базируется на незавершенной законодательно классификации преступлений, то и она имеет аналогичный изъян, а именно - искаженно отражает качественное состояние преступности. Это обстоятельство в свою очередь негативно влияет на формирование уголовной политики в борьбе с преступностью, принятие обоснованных управленческих решений в данном вопросе. Акцент при таком подходе делается на раскрытие ряда преступлений, которые, по нашему мнению, не совсем точно отнесены к категории тяжких преступлений. Само понятие тяжкого преступления в законе отражено в общем виде, не раскрыты признаки, по которым законодатель относит преступление к категории тяжких. В Основах уголовного законодательства Союза ССР и республик, принятых Верховным Советом СССР 2 июля 1991 г., нормы о классификации преступлений представлены более содержательно, однако остаются отдельные вопросы, требующие, как представляется, дальнейшей разработки. Проблема классификации преступлений в специальной литературе освещалась многими авторами (Герцензон А. А., Ковалев М. И., Анашкин Г. Э., Кригер Г. Л., Карпец И. И., Келина С. Г., Загородников Н. И., Багрий-Шахматов А. В., Шишов О. Ф., Кривоченко Л. Н., Сахаров А. Б., Кузнецова Н. Ф., Махоткин В. П., Кардаев Н. С., Фефилова В. П. и др.), но конкретных исследований на диссертационном уровне, отражающих особое положение категории тяжких преступлений, не проводилось. Значимость такого исследования и обусловила выбор настоящей темы.

Цель и задачи исследования. Основная цель исследования состоит в том, чтобы с позиций уголовного права, криминологии и правоприменительной деятельности: а) изучить эффективность действия закона о тяжком преступлении; б) разработать предложения по совершенствованию как классификации преступлений в целом, так и категория тяжких преступлений в частности; в) рассмотреть целесообразность и обоснованность отнесения конкретных преступлений к категории тяжких; г) проанализировать нормы, закрепляющие уголовно-правовые последствия, предусмотренные для лиц, совершивших тяжкие преступления, и выработать предложения по их совершенствованию; д) основываясь на теоретических выводах по совершенствованию норм уголовного закона о тяжком преступления, предложить рекомендации, направленные на повышение эффективности борьбы с такими преступлениями. Все это предполагает решение следующих задач: 1. Изучение теоретических основ классификации преступлений. 2. Анализ истории развития норм о классификации преступлений и анализ действующего законодательства. 3. Выделение степени общественной опасности преступного деяния как материального критерия классификации преступлений и её формального критерия - санкции уголовно-правовой нормы. 4. Разработка и анализ признаков, характеризующих степень общественной опасности тяжкого преступления. 5. Комплексное рассмотрение норм уголовного закона о тяжком преступлении и последствиях, наступающих для лиц, совершивших такие преступления. 6. Обобщение практики деятельности правоприменительных органов по борьбе с тяжкими преступлениями. 7. Разработка и внесение предложений по совершенствованию соответствующих норм уголовного закона.

Методологическую основу исследования составляют теоретические положения материалистической диалектики, литература по фило- 
софии, логике. В качестве юридической основы использовались нормы действующего уголовного, уголовно-процессуального, исправительнотрудового и других отраслей права. Важная роль отведена анализу уголовного законодательства дореволюционной России и других государств. Многие аспекты работы рассматривались в развитие Основ уголовного законодательства Союза ССР и республик, принятых 2 июля 1991 г.

В диссертации применен метод историзма, позволяющий раскрыть диалектику единичного и общего в подходе и классификации преступлении. Использовались и другие методы: сравнительный, логико-юридический, системного подхода, конкретно-социологический (с использованием частных методик в форме анкетирования, экспертного опроса научных и практических работников), проанализирована статистическая отчетность МВД СССР о борьбе с тяжкими преступлениями за 1985-1990 гг.

Научная новизна заключается в том, что впервые комплексно исследована тема о выделении особой группы преступных деяний, отнесенных к категории тяжких преступлений.

На защиту выносятся следующие положения диссертации:

1. Классификация преступных деяний по степени их общественной опасности, предложенная в Основах уголовного законодательства 1991 г. носит позитивный характер, способствуя осуществлению принципа дифференциации уголовной ответственности, поскольку обеспечивает гарантии для четкой индивидуализации наказания.

2. Формальным критерием такой классификации, отражающей различную степень общественной опасности, выступает санкция уголовноправовой нормы. Классификация преступлений по указанному критерию позволяет достаточно четко формулировать, исходя из тяжести деяний, содержание большинства норм и институтов Общей и Особенной частей уголовного закона.

3. Категория тяжких преступлений - особая группа умышленных деяний, совершение которых влечет наиболее суровые последствия, что и должно быть закреплено в уголовном законе. В этой связи предлагаются некоторые изменения в содержании норм о тяжких преступлениях.

4. Признаки, образующие понятие тяжкого преступления, следует считать основой при решении вопроса об отнесении конкретного преступного деяния к категории тяжких преступлений.
5. Предполагается, что борьба с преступностью вообще находится в прямой зависимости от состояния борьбы с тяжкими преступлениями. Но на борьбу с преступностью негативно влияет существующая система учета преступлений и оценки эффективности деятельности органов внутренних дел. Из-за уравнивания (через категорию тяжких преступлений)не тождественных по степени общественной опасности деяний статистическая отчетность отражает успехи в борьбе с преступностью преимущественно за счет некоторых очевидных, ситуативных преступлений, которые, кроме того, необоснованно отнесены к категории тяжких.

6. В основу учета преступлений необходимо положить классификацию, предложенную в Основах уголовного законодательства 1991 г., исключив данные о преступлениях, не представляющих большой общественной опасности, которые правильнее было бы именовать уголовными проступками.

Практическая значимость исследования заключается в том, что полученные результаты могут быть использованы при разработке уголовного законодательства республик, и, в частности, при отнесении конкретных составов преступлений к категории тяжких и определении правовых последствий для лиц, совершивших такие преступления. Отдельные выводы применимы в подготовке предложений, касающихся системы учета преступлений, и в практической деятельности правоприменительных органов. Ряд положений предлагается использовать в учебном процессе при изучении институтов Общей части уголовного закона.

Апробация результатов исследования. Диссертация подготовлена на кафедре уголовного права ВЮЗШ МВД РСФСР. Отдельные положения и работа в целом докладывались на заседаниях кафедры и получили одобрение. Основные теоретические и практические выводы по результатам исследования изложены в 3-х опубликованных статьях, доложены на научной конференции адъюнктов и соискателей «Совершенствование деятельности органов внутренних дел в условиях решительного усиления борьбы с преступностью» в 1990 г.

Структура и содержание работы. Диссертация выполнена в объеме, соответствующем требованиям ВАК при Совете Министров СССР. По структуре работа состоит из введения, двух глав, заключения, списка использованной литературы и приложений. 
Во введении обосновывается актуальность темы исследования, его практическая значимость. Определяются цели и задачи, указывается методологические основы и эмпирическая база. Сформулированы положения, выносимые на защиту.

Первая глава - «Классификация преступлений (вопросы теории и практики)» включает три параграфа, которые посвящены историческим, философским и юридическим аспектам классификации преступлений. Определяющим в исследовании классификации является такой подход, из которого вытекает, что классификация является не только методом, способом познания реалий объективного мира, но в то же время это есть и результат, научно-обоснованный вывод об объеме ранее полученных знаний. Поэтому при решении вопроса о классификации преступлений следует применять логические правила, обязательные для любой классификации.

Насущную необходимость классификации преступлений подтверждает и исторический анализ развития уголовного законодательства. Классификация преступлений присутствовала в уголовном законодательстве дореволюционной России, причем в качестве основы становления такой классификации использовалось законодательство западноевропейских государств. Наиболее разработанными с юридической точки зрения представляется нормы о классификации преступных деяний, исходя из их тяжести, в Уголовном Уложении 1903 года. Уложение предусматривало трехчленное деление преступных деяний в зависимости от тяжести налагаемых за их совершение наказаний.

Анализ развития уголовного законодательства после 1917 г. показывает, что в силу ряда объективных и субъективных факторов не произошло должной преемственности в отношении норм о классификации преступлений. Возобладал классовый подход в формировании различных групп и видов преступных деяний, а впоследствии классификация преступлений вообще утратила свое практическое значение.

В дальнейшем в содержании различных норм уголовного законодательства нашего государства проявлялась объективная необходимость классификация преступлений, исходя, прежде всего, из степени их существенной опасности. Начало этому процессу было заложено в Основах уголовного законодательства Союза ССР и союзных республик 1958 г., где фрагментарно восстанавливалось деление преступлений на различные группы. Следующим важным этапом в формировании нормативной базы, служащей более четкой классификации преступлений, безусловно, явилось введение в уголовное законодательство нормы о тяжком преступлении в 1972 г. В ст. 7-1 Основного уголовного законодательства (1958 г.) и в соответствующих статьях УК союзных республик было дано определение тяжкого преступления, содержался исчерпывающий перечень тяжких преступлений. Следует отметить, что хотя законодатель и сделал важный шаг в развитии норм о классификации преступлений, этот шаг оказался весьма осторожным. С одной стороны, критерием тяжести признавалось содержание общественной опасности, а с другой стороны, это в достаточной мере не было связано с санкциями, указанными в статьях Особенной части уголовных кодексов.

В 1977 г. в соответствии с требованиями о более четкой дифференциации ответственности, в ст. 43 Основ уголовного законодательства (1958 г.) внесены дополнения о выделении группы преступлений, но представляющих большой общественной опасности, но в то же время не умазывались признаки таких деяний и отсутствовал их перечень.

Вместе с тем следует отметить, что такая классификация преступлений сыграла положительную роль в правоприменительной деятельности и служит важным фактором в осуществлении дифференциации уголовной ответственности и индивидуализации наказания. В то же время нельзя отрицать, что классификация преступлений в действующем законодательстве нуждается в совершенствовании, требует глубокого научного обоснования. Необходимо выделить единый критерий подобной классификации и указать в законе признаки групп деяний, выбранных в качестве классификационных единиц. Очень важно было бы попытаться через классификацию преступлений в Общей части уголовного закона очертить круг уголовноправовых последствий для лиц, совершивших такие деяния.

Несовершенство классификации преступлений в действующем законодательстве отметили 96 \% практических и 92 \% научных работников, опрошенных в ходе экспертного опроса специалистов. 91 \% проинтервьюированных научных и 88 \% практических сотрудников высказались за введение в Общую часть уголовного закона специальной нормы о классификации преступлений с учетом степени их общественной опасности. 
По поводу выбора критерия классификации преступлений и по другим аспектам длиной проблемы в теории уголовного права высказываются различные точки зрения. Автор разделяет позицию тех ученых, которые считают, что критерием классификации преступлений в Общей части уголовного закона служит степень общественной опасности преступления, которая формализовано отражается в санкции конкретной статьи уголовного закона. Автором в этой связи предлагается следующее определение санкции: это формализованный критерий классификации преступлений, который непосредственно через размер и вид наказания выражает в сжатой и концентрированной форме степень общественной опасности преступления.

Выделяя в качестве такого критерия санкцию статьи, диссертант отмечает, что в советском уголовном праве подход к установлению санкций не отличается достаточной глубиной и обоснованностью. Подтверждение тому санкции статей в действующих уголовных кодексах, в которых нет единства. По мнению автора, виды и размеры санкций зачастую научно не обоснованы, что представляет одну из главных проблем уголовного права. В связи с этим следовало бы решить такую важнейшую задачу, как установление типовых санкций (то есть размеров наказания для каждой категории преступлений) научное обоснование соответствия размера наказания тяжести совершенного преступления. В работе поддержано мнение о выделении в качестве основания типовых санкций, используемых для классификации преступлений, такого наиболее строгого вида наказания, как лишение свободы.

Нормы о классификации преступлений, сформулированные в Основах уголовного законодательства Союза ССР и республик, принятых Верховным Советом 2 июля 1991 г., в целом отвечают задачам более четкой дифференциации уголовной ответственности. Но вместе с тем, возможности их дальнейшего развития и разработки не исчерпаны. Сказанное касается в первую очередь типовых санкций в виде лишении свободы, в которых по-прежнему отсутствует нижний и верхний пределы. Автор также считает необходимым дополнить норму о классификации преступлений самим понятием классификации, из которого вытекали бы её цели и задачи. Кроме того, при характеристике категорий преступлений вновь не выделяются отличительные признаки, по которым деяние относится к той или иной группе, что может затруднить в последующем распределение конкретных составов преступлений по отдельным категориям.

В третьем параграфе главы первой автором рассматривается и обосновывается значение классификации преступлений по степени их общественной опасности для построения норм и институтов Общей и Особенной частей уголовного закона и других отраслей законодательства. Диссертант солидарен с мнением большинства ученых о том, что действующая система учета преступлений, построенная только на выделении в уголовном законе категории тяжких и иных преступлений, не способствует правильной постановке основных задач уголовной политики. В связи с этим в работе предлагается в основу учета преступлений как можно скорее положить нормы о классификации преступлений по степени их общественной опасности, содержащиеся в Основах уголовного законодательства, принятых 2 июля 1991 г.

Исследование исторического и теоретического аспектов рассматриваемого вопроса привело к формулированию понятий и определенных выводов. Прежде всего, следует отметить, что классификационная проблема в науке вообще, и в юридической науке в частности, имеет большое теоретическое и практическое значение для правильного восприятия и познания реалий объективной материи. Классификация преступлений в Общей части уголовного закона есть разграничение преступлений на отдельные категории по степени их общественной опасности (тяжести), которая выражена в типовой санкции и которая предусматривает специфические для каждой категории уголовно-правовые последствия. Категория преступлений - это обособленная группа определенных видов преступных деяний, выделяемых в уголовном законе, которые связаны между собой равнозначной степенью общественной опасности, выражаемой через типовую санкцию, и за совершение которых предусмотрены специфические уголовно-правовые последствия.

Вторая глава - «Категория тяжких преступлений по советскому уголовному праву» - посвящена анализу норм уголовного закона, содержащих понятие и признаки категории тяжких преступлений (ст. 7-1 Основ уголовного законодательства 1958 г. и ст. 7-1 УК РСФСР), и норм, закрепляющих данную классификационную единицу в Основах уголовного законодательства 1991 г. Рассматривается также и система уголовно-правовых последствий, предусмотрен- 
ная законом при совершении виновным лицом тяжкого преступления.

Анализ категории тяжких преступлений, по мнению диссертанта, представляется особо значимым по ряду обстоятельств. Во-первых, накоплен определенный исторический и практический опыт применения норм о тяжком преступлении. Во-вторых, в последнее время (особенно с 1988 г.) наметилась опасная тенденция роста тяжких преступлений. Так, если в 1988 г. отмечался рост зарегистрированных преступлений на 3, 8 \%, то в 1989 г. общее количество преступлений выросло на $31,8 \%$, а количество тяжких преступлений увеличилось на 42, 3 \%. Среди тяжких преступлений особо следует выделить рост корыстнонасильственных деяний. В 1988 г. отмечен рост: умышленных убийств на $14 \%$, тяжких телесных повреждений на 31, 6 \%, изнасилований на 5, 3 \%, разбоев на 42, 6 \%, грабежей на 44, 4 Д. Количество умышленных убийств в 1969 г. увеличилось на 28 $\%$, изнасилований на 23, 9 \%, тяжких телесных повреждений на 38, 4 \%, разбоев на 71; 7 \%, грабежей на 66, 3 \%. Тревогу вызывает данные и за 1990 г.: число тяжких преступлений по сравнения о тем же периодом 1989 г. возросло на 19\%. Следует признать, что переход общества из одного качественного состояния в другое, глубокие реформы в экономике и политике, как ни парадоксально, негативно влияют на состояние преступности. Вместе с тем нельзя отрицать и тот факт, что действующее законодательство не вполне отвечает существующим реалиям. В нем в первую очередь, не четко выделяются понятие и привязки тяжкого преступления. По этой причине и категории тяжких преступлений оказались уравненными не равноценные по степени общественной опасности деяния. Данное обстоятельство приводит к ошибкам в правоприменительной практике, к принятию необоснованных решений и осуществления задач уголовной политики, неверному отражению качественного состоянии преступности.

Экспертный опрос практических работников показал, что 90 \% из них не удовлетворены понятием тяжкого преступления, содержащимся ж ст. 7-1 УК РСФСР. Более того, 61 \% опрощенных судей ж 84 \% работников прокуратуры считают, что в законе необходимо указать конкретные признаки, по которым деяние следовало бы отнести к категории тяжких преступлений.

Полагаем, что в нормах классификации преступлений, содержащихся в Основах уголовного законодательства, принятых 2 июля 1991 г., вновь исчерпывающе не раскрыты понятие и призна- ки тяжкого преступления. Указываются лишь два признака - форма вины (умысел) ж типовая санкция. По-прежнему не совсем ясно, какие деяния следует относить к данной категории. В этой связи отмечается, что в ст. 7-1 действующего УК РСФСР оказались объединены особо тяжкие и тяжкие преступления, хотя во вновь принятых Основах уголовного законодательства специально выделяется категория особо тяжких преступлений, однако признаки таковых не раскрывается. С учетом последнего обстоятельства автор предлагает определение особо тяжкого преступления и на основе этого определения считает возможным отнести к данной категории преступных деяний преступления, предусмотренные ст. 64-68, 72, 77, 7. - 1 ч. 2, 102, 103, 117 ч. 4, 191-2. 213-2 ч. 3 УК РСФСР. При этом диссертант поддерживает позицию об отмене смертной казни за совершение особо тяжких преступлений с заменой этой моры наказания на пожизненное заключение.

Далее в работе исследуется содержание степени общественной опасности преступлений, которые следует отнести и категории тяжких. Делается вывод, что содержание степени опасности таких деяний определяется совокупностью объективных и субъективных признаков. В основе лежит ценность объекта, охраняемого уголовным законом, а именно: жизнь и здоровье человека, собственность, порядок управления, деятельность государственных учреждений и органов правосудия. Но отличие тяжких преступлений от особо тяжких заключается в том, что посягательства на указанные ценности совершаются с причинением меньшего вреда и не столь опасными способами.

Проведенный анализ действующего законодательства показывает, что объективные признаки тяжкого преступления обусловлены: насилием над личностью (20\%), повторностью деяния (16 \%), тяжестью последствий (25, 3 \%). Субъективные признаки распределены следующим образом: низменные мотивы - 2, 7 \%, предварительный сговор - $15 \%$, особо опасный рецидив - $10 \%$. Нельзя не выделить и стержневой признак - умышленную форму вины. Автор присоединяется к мнению тех ученых, которые считают невозможным отнесение неосторожных преступлений к категории тяжких. Такое же мнение высказали 75 \% опрошенных специалистов.

В работе предложено следующее определение тяжкого преступления: это умышленное действие, посягающее на жизнь и здоровье 
человека, собственность, порядок упрощения, деятельность государственных учреждений и органов правосудия, совершенное опасным способом или причинившее тяжкие последствия, за которое по закону предусмотрено наказание в виде лишения свободы на срок от 5 до 10 лет.

В целях более четкой дифференциации уголовной ответственности автор полагает необходимым провести внутри категории тяжких преступлений деление на подклассы, то есть осуществить индексацию тяжких преступлений на определенные группы. Такая индексация, по мнению диссертанта, является, по сути, более тщательной классификацией и позволяет сузить сферу субъективного усмотрения судей при назначении размера наказание за конкретное преступление. В качестве определяющего признака индексации предлагается учитывать такой фактор, существенно повивающий степень общественной опасности деяния, как насилие над личностью в процессе совершения преступных действий. При этом подчеркивается особая роль, которая отводится в настоящее время важнейшему объекту уголовно-правовой охраны - личности человека.

С учетом этого автор выделяет следующие группы тяжких преступлений:

1. Преступления под индексом А - преступные посягательства, совершенные с насилием, опасным для жизни и здоровья человека.

2. Преступления под индексом Б - деяния, совершенные с насилием, не опасным для жизни и здоровья.

3. Преступления под индексом В - деяния, совершенные без насилия. Соответственно различными должны быть и размеры санкций по данным группам преступлений. В качестве примера приводится подобная классификация преступных посягательств в законодательстве США, где, исходя из санкций, представлены и категории преступных деяний, и классы внутри категорий, и даже подклассы.

Во втором параграфе главы второй дается анализ конкретных составов преступлений, включенных законодателем в перечень тяжких преступлений. При этом используются данные статистического учета преступности, результаты судебной практики. Свои выводы автор подтверждает с помощью составленных им графиков, объективно отражающих положение дел в борьбе с тяжкими преступлениями за период с 1985 по 1990 г.

На основе проведенных исследований следует заключение о необоснованности отнесения отдельных составов преступлений к категории тяжких. Это касается, в частности, преступлений, предусмотренных ст. ст. 88, 154 ч. ч. 2, 3 (в настоящее время ответственность предусмотрена по Закону СССР от 31 октября 1990 г. «Об усилении ответственности за спекуляцию, незаконную торговую деятельность и за злоупотребления в торговле»), 206 ч. 2 УК РСФСР. В то же время диссертантом поддерживается предложение об отнесении к категории тяжких преступлений деяния, предусмотренного ч. 2 ст. 121 УК РСФСР, так как насилие над личностью, унижение в таких формах человеческого достоинства, дают основание считать степень общественной опасности данного преступления соответствующей признакам тяжкого преступного деяния.

Опираясь на предложенную систему индексов внутри категории тяжких преступлений, автор предлагает выделение соответствующих групп конкретных преступлений в Особенной части уголовного закона. Так, к тяжким преступлениям под индексом А следует отнести деяния, предусмотренные ст. ст. 74 ч. 3, 77-1 ч. 1, 79, 91, 93-1 (совершенное путем разбойного нападения), 95 ч. 3 ; 96 ч. $2 ; 108 ; 117$ ч. ч. 2,$3 ; 126-1$ ч. $2 ; 146 ; 148$ ч. $3 ; 149$ ч. $2 ; 213$ ч. ч. 2,$3 ; 218-1$ ч. $3 ; 224-1$ ч. 3 УК РСФСР. К тяжким преступлениям под индексом Б следует отнести деяния, предусмотренные ст. ст. 74 ч. 2 ; 90 ч. ч. 2, 3, 4; 117 ч. 1; 93-1 (совершенное путем грабежа); 121 ч. 2; 126-1 ч. 1; 145 ч. 4. $2,3,4 ; 179$ ч. 2 ; 206 ч. 3; 224-1 ч. 2 УК РСФСР. К тяжким преступлениям под индексом В следует отнести преступления, предусмотренные ст. ст. $69 ; 70$ ч. $3 ; 78 ; 86 ; 87 ; 89$ ч. $4 ; 92$ ч. ч. 2,$3 ; 93$ ч. 3 ; 93-1 (совершенное путем крахи, растраты, присвоения, мошенничества), 173; 174 ч. $2 ; 174-1$ ч. $2 ; 176$ ч. $2 ; 177$ ч. $2 ; 218-1$ ч. 1,$2 ; 223-3 ; 224$ ч. ч. 1, 2; 231-1 ч. 1 УК РСФСР. В третьем параграфе главы второй рассматривается такой важный аспект, как уголовно-правовые последствия, наступление которых предусмотрено уголовным законом для лиц, виновных в совершении тяжких преступлений. При этом автор поддерживает мнение тех ученых, которые выступает за законодательное закрепление всей системы уголовноправовых последствий как составного элемента классификация преступлений. Предполагается, что система уголовно-правовых последствий должна быть строго увязана с тяжестью деяния, а не определяться назначенным судом наказанием. С учетом этого диссертант полагает возможным внести определенные коррективы в содержание норм уголовного закона, определяющих 
уголовно-правовые последствия совершения тяжкого преступления. Предлагается, например, установить ответственность за приготовление к особо тяжкому преступлению и к тяжкому преступлению индекса А. Поддерживается мнение об отказа наказуемости за недонесение о преступлении, в том числе и относящегося к категории тяжких. Вместе с тем считаем необходимым сохранить уголовную ответственность при заранее не обещанном укрывательстве особо тяжких и тяжких преступлений.

Действующая норма об особо опасном рецидивисте (ст. 24-1 УК РСФСР) представляется сложной и громоздкой. Классификационные признаки используется в ограниченном виде, применяются разнопорядковые критерии (и тяжесть преступления, и назначенное судом наказание). В Основах уголовного законодательства I991 г. сохранен аналогичный подход. Диссертант поддерживает вариант построения норм о рецидиве преступлений, сформулированный в теоретической модели уголовного кодекса [1]

Кроме того, в работе предлагается совершенствование и других норм, закреплявших уголовно-правовые последствия. Это относится и содержанию ст. ст. 48 и 49 (сроки давности) УК РСФСР, а к содержанию ст. ст. 53 и 53-1 (условнодосрочное освобождение от наказания и замена наказания более мягким), 57 (судимость) УК РСФСР. Автором проанализирован ряд норм, касающихся уголовно-правовых последствие, предусмотренных за тяжкие преступления, совершенные несовершеннолетними, и предложено внести и эти нормы некоторые уточнения и дополнения.

Диссертантом предлагается редакция статьи о категории тяжких преступлений:

Статья... Категория тяжких преступлений.

1. К тяжким преступлениям относятся умышленные действия, посягающие на жизнь и здоровье человека, собственность, порядок управления, деятельность государственных учреждений и органов правосудия, совершенные опасным способом или причинившие тяжкие последствия, за которые законом предусмотрено наказание в виде лишения свободы на срок от 5 до 10 лет.

2. Закон определяет следующие группы тяжких преступлений:

- тяжкие преступлена А, за совершение которых законом предусмотрено наказание в виде лишения свободы на срок от 8 до 10 лет;

- тяжкие преступления Б, за совершение которых законом предусмотрено наказание в виде лишения свободы на срок от 6 до 8 лет;

- тяжкие преступления В, за совершение которых законом предусмотрено наказание в виде лишения свободы на срок от 5 до 6 лет.

В заключении сформулированы основные выводы диссертации, наиболее значимые из которых изложены в настоящей рукописи при характеристике соответствующих разделов работы.

Результаты исследования опубликованы в следующих трудах автора:

1. К вопросу о классификации преступлений //Сборник трудов молодых ученых «Совершенствование правоохранительной деятельности органов внутренних дел. «- М.: ВЮЗШ МВД СССР. 1990. 0, 3 п. л.

2. Категория тяжких преступлений по советскому уголовному праву и проблемы правоприменительной деятельности //Сборник статей адъюнктов и соискателей «Совершенствование деятельности органов внутренних дел в условиях решительного усиления борьбы о преступностью. «- М.: ВЮЗШ МВД СССР. 1990. 0, 3 п. л.

3. Вопросы выделения категории тяжких преступлений по советскому уголовному праву //Сборник научных трудов «Проблемы совершенствования уголовного законодательства и практики его применения. «-М.: Академия МВД СССР. 1990. 0, 4 п. л.

\section{Библиография:}

1. Уголовный закон. Опыт теоретического моделирования. М., 1987. С. 110, 115.

\section{References (transliterated):}

1. Ugolovnyi zakon. Opyt teoreticheskogo modelirovaniya. M., 1987. S. 110, 115. 